\title{
Abiotic Limits for Germination of Sugarcane Seed in Relation to Environmental Spread
}

\author{
J. S. Pierre • A. L. Rae • G. D. Bonnett
}

Received: 5 August 2014 / Accepted: 8 September 2014 / Published online: 18 September 2014

(C) The Author(s) 2014. This article is published with open access at Springerlink.com

\begin{abstract}
Sugarcane is a vegetatively propagated crop and hence the production of seed and its fate in the environment has not been studied. The recent development of genetically modified sugarcane, with the aim of commercial production, requires a research effort to understand sugarcane reproductive biology. This study contributes to this understanding by defining the abiotic limits for sugarcane seed germination. Using seed from multiple genetic crosses, germination was measured under different light regimes (light and dark), temperatures (from $18{ }^{\circ} \mathrm{C}$ to $42{ }^{\circ} \mathrm{C}$ ) and water potentials (from $0 \mathrm{MPa}$ to $-1 \mathrm{MPa}$ ); cardinal temperatures and base water potential of germination were estimated based on the rates of germination. We found that sugarcane seed could germinate over a broad range of temperatures (from $11^{\circ} \mathrm{C}$ to $42^{\circ} \mathrm{C}$ ) with optima ranging from $27{ }^{\circ} \mathrm{C}$ to $36^{\circ} \mathrm{C}$ depending on source of seed. Water potentials below $-0.5 \mathrm{MPa}$ halved the proportion of seed that germinated. By comparing these limits to the environmental conditions in areas where sugarcane grows and has the potential to produce seed, water, but not temperature, will be the main limiting factor for germination. This new information can be taken into account when evaluating any risk of weediness during the assessment of GM sugarcane.
\end{abstract}

Keywords Temperature $\cdot$ Water potential · GM crops · Saccharum spp $\cdot$ Biosafety $\cdot$ Caryopsis $\cdot$ Fuzz

\section{Abbreviations \\ GM Genetically modified}

Communicated by: Paulo Arruda

J. S. Pierre $(\bowtie) \cdot$ A. L. Rae $\cdot$ G. D. Bonnett

CSIRO Agriculture Flagship, 306 Carmody Road, St Lucia, Qld

4067, Australia

e-mail: johann.pierre@csiro.au

\section{Introduction}

Sugarcane is a perennial grass cultivated in tropical and subtropical regions for the high sucrose content in the culm. The primary use of sucrose is for the food industry but it is also increasingly used for the production of bioethanol (Waclawovsky et al. 2010). In commercial fields, sugarcane plants are obtained by vegetative propagation from pieces of stalk (setts) that are planted and cultivated through multiple ratooning cycles where new shoots grow from their stubbles after harvesting. Contrary to other grass crops, the seed plays no part in the production cycle of sugarcane.

Before the 19th century, the ability of sugarcane to reproduce sexually was unknown and hence for many years, vegetative propagation was the only way to disseminate sugarcane. In 1858 , the ability of sugarcane to produce fertile seeds was observed in Java and independently re-observed in Barbados in 1859 (reviewed by Moore et al. 2014). This discovery enabled the start of sugarcane breeding programs in which modern sugarcane varieties (Saccharum spp.) were created as hybrids between Saccharum officinarum L. (sweet sugarcane) and Saccharum spontaneum L. (wild sugarcane) (Buddenhagen 1977). In recent years, sugarcane varietal improvement has reached a new stage with the ability to transform sugarcane to create genetically modified (GM) varieties (Lakshmanan et al. 2005).

In most countries, to ensure protection of environment and human health, the release and cultivation of new GM crops is subject to government regulation (Holst-Jensen 2009). As part of the assessment, the level of change between the parent variety and the GM plants in terms of spread and persistence is evaluated (Paoletti et al. 2008). Among other things, it is crucial to understand the different means for the plant to spread in its environment (vegetative propagation and/or sexual reproduction) and to assess its weediness potential. It is also important to understand whether the GM trait itself or its 
pleiotropic effects will modify the extent of spread and persistence.

Since sugarcane is vegetatively propagated, the production of seed and its fate in the environment have not been studied. However, in many sugarcane growing areas sugarcane does flower and is fertile (Berding and Hurney 2005; Bonnett et al. 2010). Consequently, this gap of knowledge needs to be addressed for a complete evaluation of GM sugarcane varieties (Cheavegatti-Gianotto et al. 2011; OGTR 2011; OECD 2013). In order to contribute to the environmental risk assessment for GM sugarcane, the effectiveness of different stages of sugarcane sexual reproduction in crop need to be understood including pollen dispersal, ability to cross with other plants, seed physiology, seedling establishment and interaction with the plant community in and around sugarcane fields.

As GM sugarcane varieties are under development, this work has gained importance and in recent years, efforts have been made to study sexual reproduction of sugarcane in commercial fields. It has been demonstrated that in Australian sugarcane growing areas, sugarcane will flower over a wide range of latitudes but will produce viable seed only in an area ranging from approximately latitude $16^{\circ} \mathrm{S}$, the northern limit of sugarcane cultivation in Australia, to $20^{\circ} \mathrm{S}$ (Bonnett et al. 2010; Pierre et al., unpublished). In studies reporting the proportion of cross- and self pollination, it was demonstrated that sugarcane is a preferentially out-crossing species (McIntyre and Jackson 2001; Tew and Pan 2010). A theoretical study of the distance to prevent contamination of controlled crosses suggested that the safe distance to prevent sugarcane cross pollination is $100 \mathrm{~m}$ in open forest and $300 \mathrm{~m}$ in open ground (Skinner 1959). Consequently cross pollination between conventional and GM sugarcane, when grown in the same area, is possible, hence increasing the likelihood to find sugarcane seed with a GM trait outside of the GM fields.

There are no published reports of sugarcane plants establishing from seed in and around sugarcane fields. In North Queensland the weather conditions at the time of seed production, July to August (Olivares-Villegas et al. 2010), of low rainfall and temperatures below $25^{\circ} \mathrm{C}$, could be the limiting factors for seed to germinate and seedlings to establish. In Panama (latitude $8^{\circ}-9^{\circ} \mathrm{N}$ ), Saccharum spontaneum, one of the parents of commercial Saccharum spp., is a major weed that establishes from seed (Bonnett et al. 2014). There, the consistently higher temperatures and significant rainfall during the seed production period seem to be key factors contributing to this successful invasion.

The fate of fertile sugarcane seeds in major sugarcane production regions in relation to the environmental conditions is largely unknown. Among other things, the cardinal temperatures for seed germination are an important parameter to consider when assessing the likelihood of seed germination in relation to the weather conditions. Previous studies on sugarcane seed germination were aimed at improving the rate of germination for breeding programs, rather than defining the upper and lower limits to germination (Dutt et al. 1937; Lee and Loo 1958; Poljakoff-Mayber 1959; Heinz 1974; Itakura et al. 1981; Cazalet and Berjak 1983; Singh 1988; Hsu 2001). Where multiple temperatures were tested, the temperatures giving the greatest number of seedlings (not necessarily statistically significant) were $37^{\circ} \mathrm{C}$ for Saccharum spontaneum L. (Poljakoff-Mayber 1959); $35{ }^{\circ} \mathrm{C}$ for one (Itakura et al. 1981) or two sugarcane seed sources (Singh 1988) or $38^{\circ} \mathrm{C}$ for 5 seed sources (Heinz 1974).

Whilst these studies have been useful for sugarcane breeding, they do not provide the base line information on the response of germination to a broad range of temperatures that would assist evaluation of GM sugarcane. First, most of the studies used only one or two crosses hence the genetic variation between families was not taken into account. The importance of water availability for seed germination, because it was irrelevant from a breeder perspective, has never been assessed before. Nevertheless for the study of limits to seed germination in relation to environmental conditions, the water availability is as important as the temperature. Furthermore, the term germination has been loosely used and does not distinguish between seed germination and seedling elongation, leading to confusion over which phenomenon was observed. Finally observations were made only on the final percentage of germination, and the range of temperatures used was not large enough to define the upper and lower temperature limits of germination.

In this paper we report the first comprehensive study on abiotic limits to germination of sugarcane seed, assessing both temperature and water availability, using seeds from multiple crosses (different parents and year of production) (Table 1). The results define the potential for germination of sugarcane seed and can be compared with the environmental conditions that are likely to be found in sugarcane growing regions at the time of seed production.

\section{Results}

Influence of Light on Germination

When tested for all crosses combined the light conditions did not influence germination ( $p$-value $=0.836$ ). However, when the test was performed for seed from each cross individually, six crosses out of eight were not significantly sensitive to light $(p<0.05)$ (Table 2). The germination of seed from two crosses were influenced by the light conditions, either positively $(98 * 78)$ or negatively $\left(89^{* 758)}\right.$. As overall, light did not appear to influence the germination, subsequent experiments were conducted in the light to help with the frequent observation of germinated seeds. 
Table 1 Parents and year of production of the seeds used in the experiment. Q: Queensland (Australia); QC: Queensland Central; QN: Queensland North; H: Hawaii (USA); F: Formosa (Taiwan); CP: Canal Point (USA); VMC: Victoria Milling company (Phillippines). GEMINI was bred in Queensland North

\begin{tabular}{llll}
\hline Cross ID & Female parent & Male parent & Year of production \\
\hline $89 * 758$ & QC73-214 & QN82-115 & 1989 \\
$91 * 684$ & Q121 & QN84-2850 & 1991 \\
$96 * 283$ & H52-663 & Q173 & 1996 \\
$98 * 2$ & F177 & QS80-7059 & 1998 \\
$98 * 78$ & QN85-2770 & CP67-412 & 1998 \\
$98 * 148$ & QN87-2029 & QN82-450 & 1998 \\
$98 * 206$ & Q174 & VMC67-315 & 1998 \\
$98 * 217$ & GEMINI & Q162 & 1998 \\
\hline
\end{tabular}

\section{Effect of Temperature on Seed Germination}

The effect of temperature on germination was assessed over temperatures ranging from $18{ }^{\circ} \mathrm{C}$ to $42^{\circ} \mathrm{C}$. At least some seeds were able to germinate at all temperatures (Fig. 1). At $18^{\circ} \mathrm{C}$ the final percentage of germinated seeds ranged from 41 to $82 \%$ while at $42{ }^{\circ} \mathrm{C}$ the final percentage of germinated seeds was either null or low $(0-13 \%)$ (Fig. 1). At $36^{\circ} \mathrm{C}$, which has been reported to be an optimal temperature for germination, the final number of germinated seeds was significantly lower than at cooler temperatures for five of the eight crosses (Fig. 1).

Seed from all crosses except $98 * 2$ showed a similar trend for their rate of germination. Seeds from cross $98 * 2$ had a slower rate of germination at all temperatures compared to the other crosses (Fig. 1).

Predicted data obtained from the fitted 3 parameter Gompertz functions were used to estimate the base and

Table 2 Effect of light on seed germination. Sugarcane seeds were incubated at $36{ }^{\circ} \mathrm{C}$ in light or dark conditions on wet filter paper for 10 days after which the number of germinated seeds was evaluated. Results are presented as mean \pm standard error

\begin{tabular}{llll}
\hline & \multicolumn{2}{l}{ Germinated seed } & \\
\cline { 2 - 4 } Cross & Light & Dark & $p$-value \\
\hline $98 * 78$ & $37 \pm 5$ & $24 \pm 1$ & 0.02 \\
$98 * 148$ & $112 \pm 6$ & $91 \pm 10$ & 0.07 \\
$98 * 206$ & $60 \pm 6$ & $67 \pm 5$ & 0.28 \\
$96 * 283$ & $47 \pm 0$ & $44 \pm 5$ & 0.50 \\
$89 * 758$ & $28 \pm 6$ & $52 \pm 8$ & 0.03 \\
$98 * 2$ & $44 \pm 9$ & $24 \pm 6$ & 0.07 \\
$91 * 684$ & $56 \pm 4$ & $69 \pm 6$ & 0.07 \\
$98 * 217$ & $44 \pm 4$ & $47 \pm 2$ & 0.46 \\
\hline
\end{tabular}

$P$-value when comparing light versus dark for all crosses combined: 0.836 optimal temperature of germination as presented in Fig. 2 and Table 3. Because the rate and final percentage of germination was low at $42{ }^{\circ} \mathrm{C}$, this temperature was not included in the analysis. Optimal temperatures of germination ranged from $27{ }^{\circ} \mathrm{C}$ to $36{ }^{\circ} \mathrm{C}$ (Table 3). Five of the trialled crosses had an optimum temperature for seed germination of $30^{\circ} \mathrm{C}$ for the temperatures assessed; $98^{*} 2$ was the only cross with an optimum of $36^{\circ} \mathrm{C}$, while the remaining two crosses had an optimum temperature of $27^{\circ} \mathrm{C}$.

To account for the variability of germination rate between replicates, two estimates of the base temperature of germination were made using the time to reach both 30 and $50 \%$ of germination (Fig. 2). The linear regressions between the inverse of the time to reach 30 or $50 \%$ of germination and temperature were strong with $r^{2}$ values above 0.95 . The two estimations of the base temperature of germination were identical or close, varying by less than $0.5^{\circ} \mathrm{C}$, for 6 of the crosses. The difference between the two estimates for $98 * 148$ was $0.6{ }^{\circ} \mathrm{C}$, but according to the $\mathrm{r}^{2}$ value the estimate for $30 \%$ of germination of $15.2{ }^{\circ} \mathrm{C}$ is more accurate. For $89 * 758$ it was not possible to estimate the base temperature of germination using $50 \%$ of germination since this level of germination was not reached at half of the tested temperatures.

Base temperatures of germination ranged from $11.2{ }^{\circ} \mathrm{C}$ to $16.4^{\circ} \mathrm{C}$ (Table 3). $98^{*} 2$ stood out from the other crosses with a relatively lower base temperature of germination of $11.2^{\circ} \mathrm{C}$ $11.4^{\circ} \mathrm{C}$. The other crosses had a base temperature varying between $13.7^{\circ} \mathrm{C}$ and $16.4{ }^{\circ} \mathrm{C}$.

At the highest temperature tested, $42{ }^{\circ} \mathrm{C}$, the final number of germinated seed was extremely low and then could not be used to estimate the upper temperature limit for seed germination. For 5 of the crosses $(89 * 758,91 * 684,96 * 283,98 * 2$ and $98 * 78$ ) the final percentage of germination was between 0 and $5 \%$ and for the three other crosses the final percentage of germination ranged between 7 and $14 \%$. These low numbers of germinated seeds at $42{ }^{\circ} \mathrm{C}$ suggest that this temperature is either above or close to the Tmax for germination depending on the crosses.

\section{Effect of Water Potential on Seed Germination}

The effect of water availability was tested on seed from 4 crosses over a spectrum of water potential ranging from $0 \mathrm{MPa}$ to $-1 \mathrm{MPa}$. The germination rate of all the crosses was affected by the decrease in water potential (Fig. 3). A decrease from 0 to $-0.5 \mathrm{MPa}$ doubled the time necessary to reach $30 \%$ germination.

The final percentage of germination of seed from cross $98 * 148$ was the most sensitive to declining water potential (Fig. 3). Seed from crosses $89 * 758$ and $98 * 206$ showed no differences in the final percentage of germination between 0 and $-0.5 \mathrm{MPa}$ but then decreased by $50 \%$ at lower water potential. Seed from cross $98 * 217$, showed no statistically 
Fig 1 Germination of fuzz of eight sugarcane crosses at different temperature regimes: $18^{\circ} \mathrm{C}, 24^{\circ} \mathrm{C}, 27^{\circ} \mathrm{C}, 30^{\circ} \mathrm{C}, 36^{\circ} \mathrm{C}$ and $42^{\circ} \mathrm{C}$ after different periods of time. Symbols represent the experimentally measured cumulative germination percentage relative to the total number of germinated seeds at $30^{\circ} \mathrm{C}$ and the lines represent the fitted Gompertz function for each temperature. Error bars denote standard error $( \pm)$. Letters represent significative differences $(p$-value $<0.05)$ between final percentages of germination

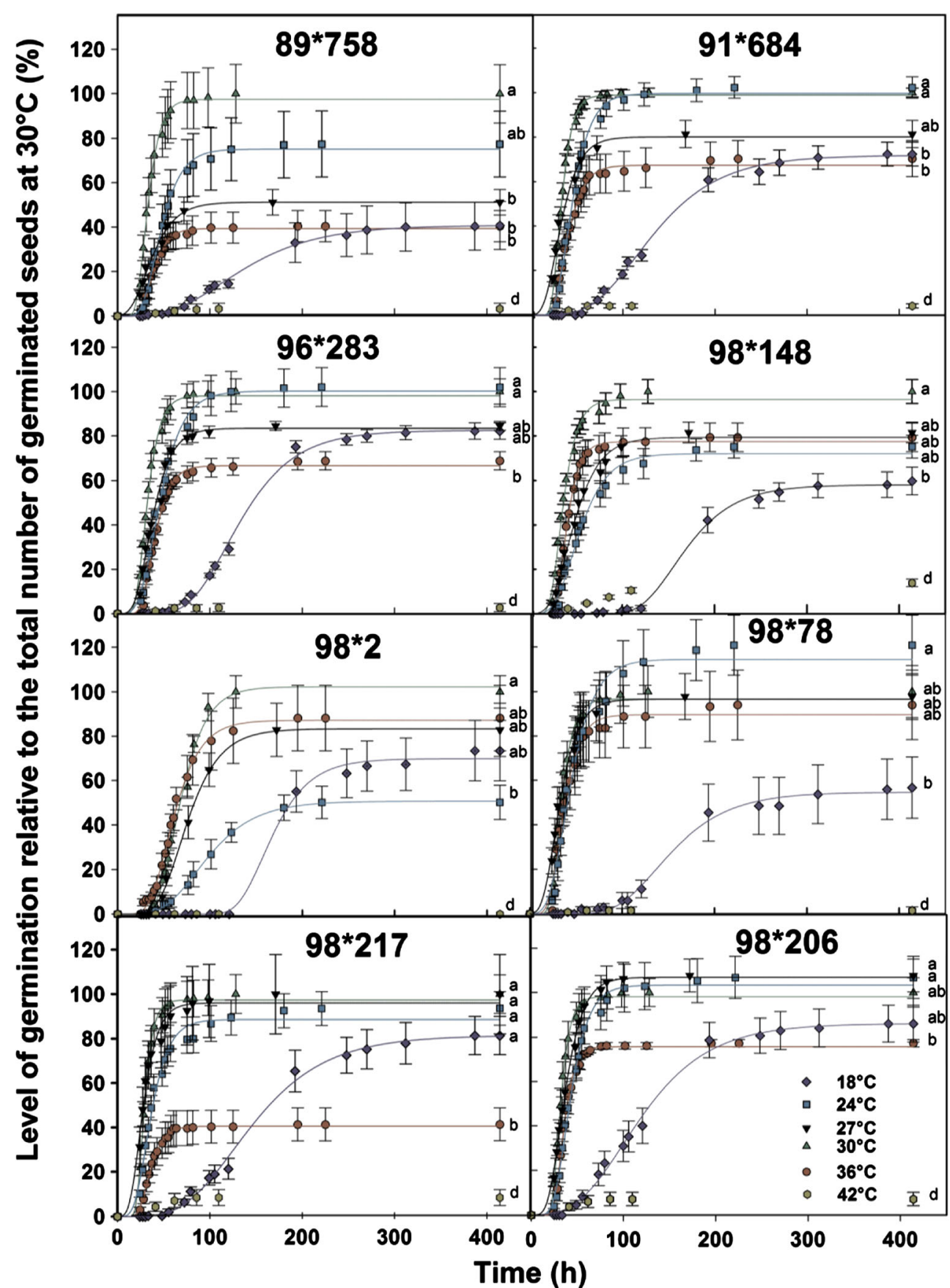

significant differences in final percentage of germination between any of the water potential tested $(p$-value $=0.06)$.

Two estimates of the base water potential of germination were made using the time to reach 30 and $45 \%$ of germination (Fig. 4 and Table 4). The $\mathrm{r}^{2}$ values for all relationships were over 0.95 except for $98 * 217$ for time to reach $45 \%$ of germination where $r^{2}$ was 0.91 . Overall the differences between the two estimates were between 0.1-0.2 MPa.

Seed from cross $89 * 758$ had the highest sensitivity to decreasing water potential with a base water potential of germination estimated to be between $[-1.1,-1.2 \mathrm{MPa}]$ and seed from cross $98 * 217$ has the lowest base water potential of germination $[-1.4,-1.5 \mathrm{MPa}]$.

\section{Discussion}

This paper is the first report defining the range of temperatures and water potentials which permit germination of sugarcane true seeds. By comparison with long-term meteorological records, this information can help to identify geographical 
Fig 2 Inverse of the time to reach $30 \%$ (circle) or $50 \%$ (square) of germination as a function of temperature. Straight lines represent the linear relationship between the two factors with the $\mathrm{x}$-intercept being the base temperature of germination

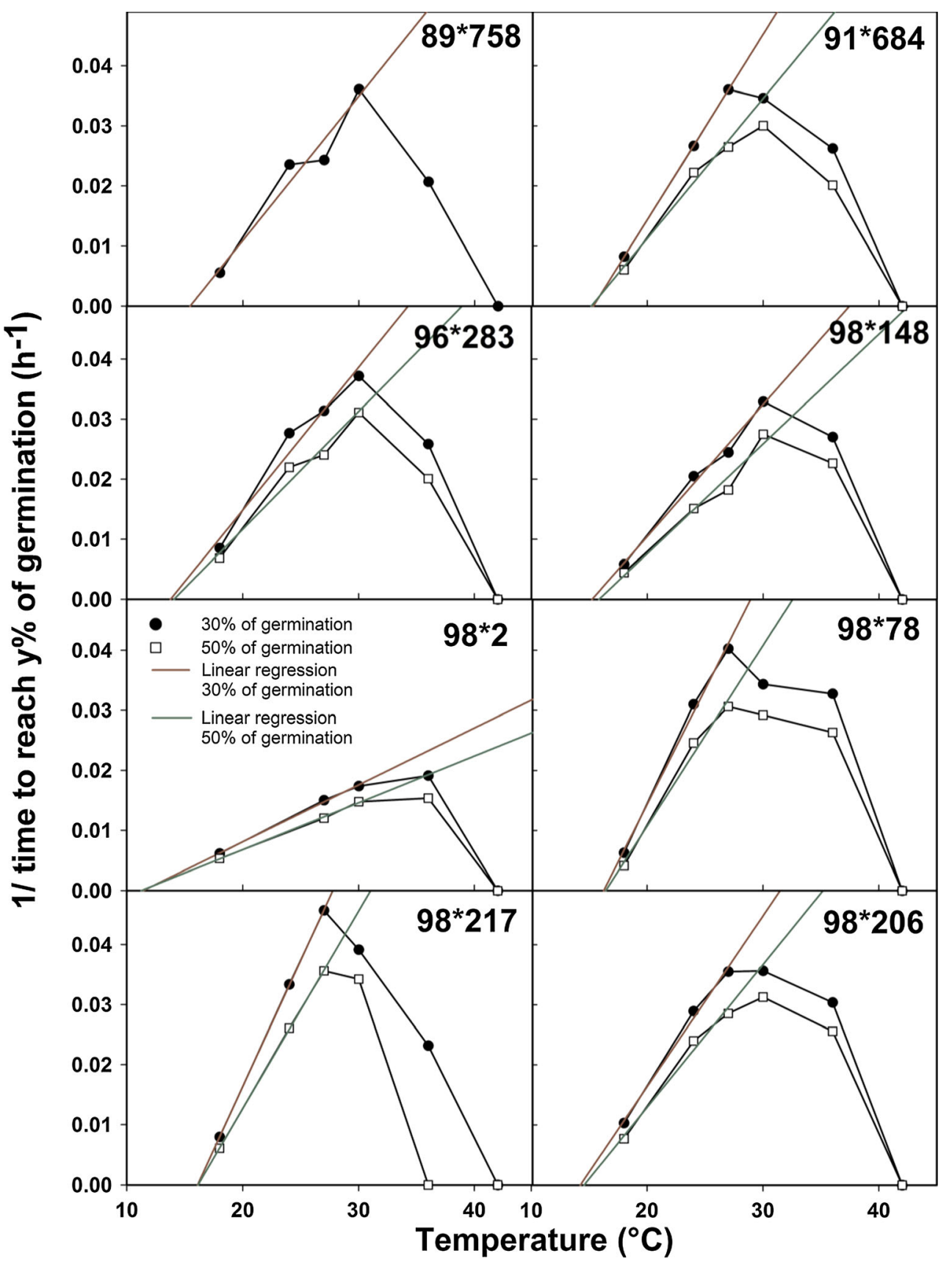

regions and climatic zones in which seeds can germinate in the environment. This characterization of the biological limits for sugarcane seed germination will serve as a reference against which potential changes in a GM variety could be compared if necessary.

In this study, the materials and the treatment conditions have been chosen to be relevant to the experienced environment in places where sugarcane grows. Temperatures and water potentials were selected within the range of conditions that may occur in sugarcane growing regions. The selected sources of seed came from eight different bi-parental crosses with 16 different parents. The results therefore encompass part of the genetic diversity that exists in sugarcane breeding germplasm. The previous studies about sugarcane seed germination had always used seeds coming from small number of varieties therefore reducing the possible impact of genetic variation on seed germination (e.g. Singh et al. 1988).

Sugarcane varieties are highly heterozygous polyploids and hence within an inflorescence, the seeds are not genetically identical. In addition the highly complex nature of the sugarcane genome leads to chromosome loss during meiosis (Cuadrado 2004) which increases the genetic variability between individual seeds. Therefore some of the variability observed between replicates in our 
Table 3 Optimum and base temperature of germination of seed from the eight crosses. Estimates of base temperatures of germination were made using the $\mathrm{x}$-intercept resulting from linear regression of the inverse of the time to reach 30 or $50 \%$ of germination as a function of temperature. The $r^{2}$ associated with each linear regression is presented as a superscript

\begin{tabular}{llll}
\hline & & \multicolumn{2}{l}{ Base temperature $\left({ }^{\circ} \mathrm{C}\right)$} \\
\cline { 3 - 4 } Cross & Optimum $\left({ }^{\circ} \mathrm{C}\right)$ & $30 \%$ & $50 \%$ \\
\hline $98 * 2$ & 36 & $11.4^{0.998}$ & $11.2^{0.998}$ \\
$98 * 148$ & 30 & $15.2^{0.995}$ & $15.8^{0.972}$ \\
$96 * 283$ & 30 & $13.7^{0.995}$ & $14.0^{0.972}$ \\
$89 * 758$ & 30 & $15.4^{0.953}$ & $\mathrm{n} / \mathrm{a}$ \\
$98 * 206$ & 30 & $14.2^{0.994}$ & $14.6^{0.985}$ \\
$91 * 684$ & 30 & $15.3^{1.00}$ & $15.2^{0.982}$ \\
$98 * 78$ & 27 & $16.2^{0.996}$ & $16.4^{0.987}$ \\
$98 * 217$ & 27 & $16.1^{1.00}$ & $16.1^{1.00}$ \\
\hline
\end{tabular}

experiments is the result of genetic diversity between seeds from the same cross.

To mimic natural conditions, fuzz instead of bare caryopsis, was used for our experiments as the caryopses normally remain tightly attached to the floret structures when florets drop from the inflorescence at maturity. The floret structures, lemma, palea and glumes, are known to restrict oxygen diffusion and to limit water movement (Simpson 1990) and increases in seed germination in dormant and non-dormant seed have been demonstrated when the caryopsis was separated from these structures (Simpson 1990). Therefore removing them may lead to different conclusions regarding the water requirement for seed germination.

Significant numbers of seeds germinated at the lowest temperature tested $\left(18{ }^{\circ} \mathrm{C}\right)$ and the estimated base temperatures of germination varied between $11.2{ }^{\circ} \mathrm{C}$ and $16.4{ }^{\circ} \mathrm{C}$. These results set a lower limit to germination temperature that is $10^{\circ} \mathrm{C}$ to $15^{\circ} \mathrm{C}$ below the temperature that was reported to strongly inhibit germination (Heinz 1974; Itakura et al. 1981; Singh 1988). In regions of Australia where fertile seed is produced in commercial fields, (latitudes $\mathrm{S}_{1} 6^{\circ}$ to $\mathrm{S} 20^{\circ}$, Bonnett et al. 2010; Pierre et al., unpublished) the mean minimal temperature during winter does not fall below $18^{\circ} \mathrm{C}$ (source: Bureau of Meteorology 2014). With on average $69 \%$ of seeds still able to germinate at $18{ }^{\circ} \mathrm{C}$, temperature is not a limitation for sugarcane seed germination at those latitudes. Similar analyses are presented for the countries that are the largest producers of sugarcane. In Brazil the main sugarcane producing area is around São Paulo where the temperatures during the coldest month of the year do not fall below $15{ }^{\circ} \mathrm{C}$ (source: World Bank 2014). In the northern part of the country, close to Maceió (Alagoas state) where sugarcane breeding also takes place and where the production of fertile seeds is more likely, temperatures don't fall below $24{ }^{\circ} \mathrm{C}$. In the southern state of Maharashtra, one of the major areas of production for sugarcane in India, the mean minimal temperatures between Solapur $\left(\mathrm{N} 17^{\circ}\right)$ to Aurangabad $\left(\mathrm{N} 19^{\circ}\right)$ are always above $20^{\circ} \mathrm{C}$ (source: World Bank 2014) and in the area of Coimbatore $\left(\mathrm{N} 11^{\circ}\right)$ where sugarcane is bred, the minimal temperatures are around $24^{\circ} \mathrm{C}$. Finally in China, in the areas of Kaiyuan $\left(\mathrm{N} 23^{\circ}\right)$ and Guangzhou $\left(\mathrm{N} 23^{\circ}\right)$, where
Fig 3 Germination of fuzz of the fourr sugarcane crosses at different water potential regimes: $0 \mathrm{MPa},-0.25 \mathrm{MPa},-0.5 \mathrm{MPa}$, $-1 \mathrm{MPa}$. Symbols represent the measured cumulative germination percentage relative to the total number of germinated seeds at $0 \mathrm{MPa}$ and the lines represent the fitted Gompertz function for each water potential. Error bars denote standard error $( \pm)$. Letters represent significative differences $(p$-value $<0.05)$ between final percentages of germination

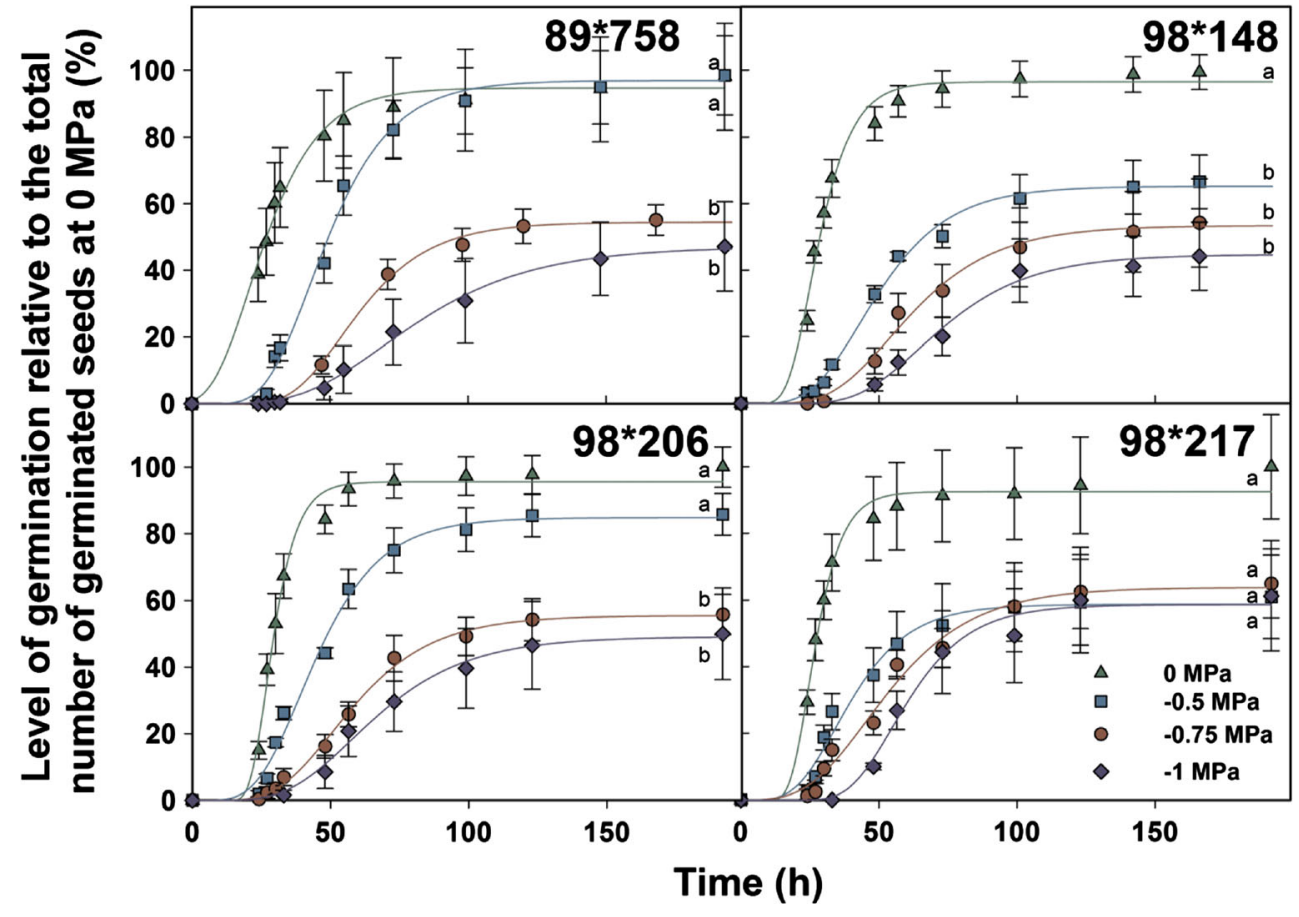


Fig 4 Inverse of the time to reach $30 \%$ (circle) or $50 \%$ (square) of germination as a function of water potential. Straight lines represent the linear relationship between the two factors with the $\mathrm{x}$-intercept being the base water potential of germination

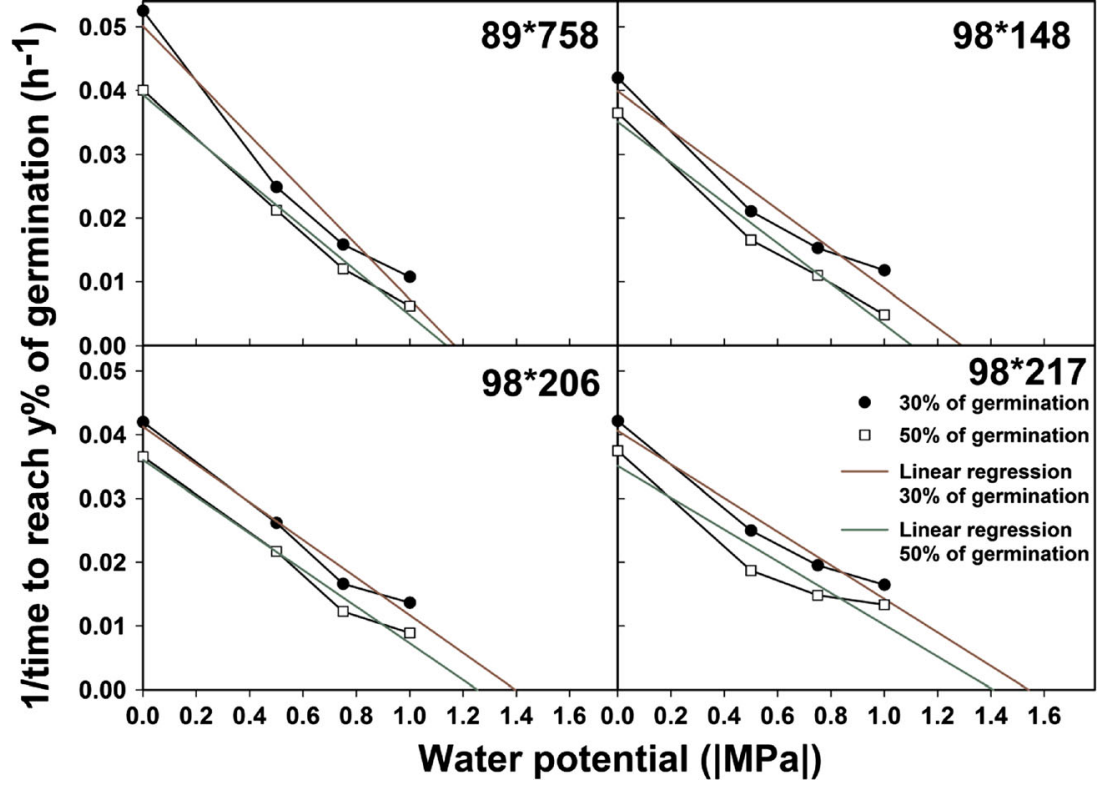

two of the Chinese sugarcane breeding institutes are located, the mean minimal temperatures are $10{ }^{\circ} \mathrm{C}$ and $13{ }^{\circ} \mathrm{C}$ respectively, reducing greatly the possibility of sugarcane seed to germinate. Except for China, if water is not a limiting factor, it is likely that a proportion of seed from some genotypes would be able to germinate under these conditions and this proportion is likely to increase with decreasing latitude. The newly defined base temperature of germination will be important data for assessing the regulation of GM sugarcane. In fact, with only the previous reports on sugarcane seed germination showing a relatively high temperature requirement for optimal germination $\left(\sim 36^{\circ} \mathrm{C}\right)$ (Heinz 1974; Itakura et al. 1981; Poljakoff-Mayber 1959; Singh 1988) there was an implied impediment for their germination at the time of their production in the field.

The optimal temperature of germination determined by this study is lower than previously published work in sugarcane. The literature on sugarcane seed germination

Table 4 Base water potential for germination of seed from the four selected crosses. Estimates of the base water potential of germination were made using the $\mathrm{x}$-intercept of the linear regression of inverse of the time to reach 30 or $45 \%$ of germination as a function of the temperature. The $r^{2}$ associated with each linear regression is displayed as a superscript

\begin{tabular}{lll}
\hline & \multicolumn{2}{l}{ Base water potential (MPa) } \\
\cline { 2 - 3 } Cross & $30 \%$ & $45 \%$ \\
\hline $89 * 758$ & $-1.2^{0.964}$ & $-1.1^{0.992}$ \\
$98 * 148$ & $-1.3^{0.953}$ & $-1.1^{0.979}$ \\
$98 * 206$ & $-1.4^{0.978}$ & $-1.3^{0.983}$ \\
$98 * 217$ & $-1.5^{0.962}$ & $-1.4^{0.910}$ \\
\hline
\end{tabular}

reports an optimal temperature of germination around $37{ }^{\circ} \mathrm{C}$ for Saccharum spontaneum (Poljakoff-Mayber 1959); and $35{ }^{\circ} \mathrm{C}$ to $38{ }^{\circ} \mathrm{C}$ for Saccharum spp. (Heinz 1974; Itakura et al. 1981; Singh 1988). For seed from 7 of the 8 crosses, the optimal temperature of germination was significantly lower, ranging from $27{ }^{\circ} \mathrm{C}$ to $30^{\circ} \mathrm{C}$. We demonstrated that $36{ }^{\circ} \mathrm{C}$ is a supra optimal temperature for germination that leads to a slower rate of germination and a decreased number of germinated seeds for a majority of the samples tested. These results are of importance to sugarcane breeding programs, where seedlings are frequently germinated at $35^{\circ} \mathrm{C}$ (Breaux and Miller 1987). Use of lower temperatures should be investigated to test whether it improves both the rate and number of seedlings raised.

In tropical cereals where the seed is the basis of propagation and production, the conditions that allow seed germination are well defined. The cardinal and optimal temperatures for seed germination of the main tropical cereal crops are $6{ }^{\circ} \mathrm{C} / 43{ }^{\circ} \mathrm{C} / 34{ }^{\circ} \mathrm{C}$ for maize (Itabari et al. 1993), $8.5{ }^{\circ} \mathrm{C} / 49{ }^{\circ} \mathrm{C} / 35{ }^{\circ} \mathrm{C}$ for sorghum (Harris et al. 1987); $10{ }^{\circ} \mathrm{C} / 45{ }^{\circ} \mathrm{C} / 30{ }^{\circ} \mathrm{C}$ for rice (Yoshida 1981) and $12{ }^{\circ} \mathrm{C} / 48{ }^{\circ} \mathrm{C} / 34{ }^{\circ} \mathrm{C}$ for pearl millet (Garcia-Huidobro et al. 1982). Sugarcane has a base temperature of germination which is higher than these tropical grass crops and a maximal temperature of germination which we assume to be close to the one for maize $\left(>42{ }^{\circ} \mathrm{C}\right)$. It is likely that selection for efficient seed germination in the tropical cereals has resulted in a broader adaptation to climatic conditions than has occurred in sugarcane, which has not undergone any selection for seed traits. Base temperatures for other developmental stages of sugarcane have been defined and it appears that vegetative sett "germination" is 
less sensitive to cold than seed germination with a base temperature around $10.8{ }^{\circ} \mathrm{C}-12.7{ }^{\circ} \mathrm{C}$ (Humbert 1968; Yang and Chen 1980; Donaldson 2009).

The availability of water is a key factor in seed germination. Low water potential will slow down the germination process due to an increased difficulty for the seed to extract water from its surrounding media. Depending on the species and the intensity of the water deficit, it will inhibit or greatly compromise germination. In our experiments we have shown diverse response of sugarcane seed germination to decreasing water potential. For three of the tested crosses the final percentage of germination was not significantly affected by mild water deficit $(-0.5 \mathrm{MPa})$. Except for $98 * 217$, subsequent decrease in water potential impacted significantly the final number of germinated seeds reducing it by nearly half. The heterogeneous response to decreasing water potential between the crosses results in a wide range of base water potential of germination estimated between -1.1 and $-1.5 \mathrm{MPa}$. As a comparison, bud outgrowth from setts and subsequent root elongation is significantly reduced when soil water potential equals $-0.5 \mathrm{MPa}$ and bud outgrowth is minimal between -2.0 to $-3.0 \mathrm{MPa}$. (Singh and Srivastava 1974). In regards to other cereal crops, sugarcane germination response to water deficit is close to that observed for sorghum (Stoutt et al. 1980) and barley (Zhang et al. 2010). For sorghum, the ability to germinate under water deficit is highly dependent on the variety. Some varieties will achieve $100 \%$ of germination at $-0.6 \mathrm{MPa}$ while at this same water potential other varieties will barely reach $20 \%$. For barley, the final percentage of germination at $-0.9 \mathrm{MPa}$ was $70-73 \%$ and then dropped dramatically at lower water potential. By contrast wheat seeds will achieve a high level of germination for soil water potential values that are below sugarcane permanent wilting point of $-1.5 \mathrm{MPa}$ (Inman-Bamber et al. 1998) with more than $75 \%$ of germination at -1.6 MPa (Wuest and Lutcher 2013; Hampson and Simpson 1990).

Where fertile sugarcane seeds are produced in Australia, it happens during the driest time of the year with monthly rainfall between $40-70 \mathrm{~mm}$ and mean maximal temperature around $26{ }^{\circ} \mathrm{C}$ (source: Bureau of Meteorology 2014). This combination of low rainfall and high temperature favours drying of the soil surface. In such environments seed germination and subsequent root elongation needs to happen quickly for the root to reach soil layers less depleted in water to supply water demand for seedling establishment. Our results show that decreasing water potential considerably slows down the germination process and for most crosses water potentials below $-0.5 \mathrm{MPa}$ greatly affect the final percentage of germinated seeds. Therefore water availability at the time of seed ripening and release seems to be the main limiting factor for seed germination in sugarcane growing areas where viable seed are produced. Nonetheless, in other parts of the world water availability at the time of seed setting is not a limiting factor. For example, in Panama (latitude $6^{\circ} \mathrm{N}-7^{\circ} \mathrm{N}$ ) Saccharum spontaneum, one of the progenitor species of modern sugarcane, is a weed of major importance (Saltonstall and Bonnett 2012). Its flowering and seed setting occur during a time of the year where monthly average rainfall is between $300 \mathrm{~mm}$ to $500 \mathrm{~mm}$ (source: World Bank 2014) resulting in massive populations that the genetic evidence suggests are growing from seeds (Bonnett et al. 2014).

In conclusion, our data provide important information about sugarcane reproductive biology which will assist the scientific evidence-based regulation of genetically modified sugarcane. Whilst temperature does not appear to be a limiting factor in most areas where sugarcane is grown, the water availability at the time of seed production seems to be a major limiting factor for germination. Therefore, water availability at the time of seed production needs to be taken into account to evaluate the likelihood of GM cane establishment from seed. A further key question will be whether seed can persist in the environment until periods of increased rainfall occur.

\section{Material and Methods}

\section{Seed Material}

Seed (caryopsis) was sourced from eight bi-parental sugarcane crosses made at Meringa (Sugar Research Australia (SRA), formerly BSES Ltd.) $\left(17^{\circ} 3^{\prime} 52.63^{\prime \prime} \mathrm{S}, 145^{\circ} 46^{\prime} 27.72^{\prime \prime} \mathrm{E}\right)$ in northern Queensland, between 1989 and 1998 (Table 1), with parents originating from a range of countries (Table 1). Breeder cross material was used because it provides large quantity of highly fertile material which is not possible to obtain from field samples.

After harvesting the inflorescence, the fuzz (a mixture of sterile and fertile florets) was dried for 5 days at $12{ }^{\circ} \mathrm{C}$ and $10 \%$ humidity then packed in sealed polypropylene bags and stored at $-20^{\circ} \mathrm{C}$. In December 2012, bags were transferred to a cold room at $3{ }^{\circ} \mathrm{C}$ at $31 \%$ relative humidity.

Sugarcane seed is very small (approximately $1.8 \mathrm{~mm} \times$ $0.8 \mathrm{~mm}$ ) and tightly enclosed in bracts (Cheavegatti-Gianotto et al. 2011, De Siqueira et al., submitted). In our experiments, to mimic natural conditions, seeds were not separated from the fuzz and fuzz was not sterilized for the germination experiments. The amount of fuzz put into each box was determined through a germination test conducted at $36{ }^{\circ} \mathrm{C}$ with and without light $(n=5)$ and corresponded to an average number of 30 to 60 germinated seeds per replicate (Table 2).

Influence of Light on Seed Germination and Early Growth

Light can influence germination of seeds (Frankland and Taylorson 1983). For sugarcane hybrids there are no 
statistically analysed comparisons of germination in the light and dark, though Itakura et al. (1981) suggested that light improved germination. Consequently we tested the effect of light on the germination of the eight seed sources. Fuzz $(0.3 \mathrm{~g})$ was evenly spread onto filter paper (Whatman, filter paper $3,125 \mathrm{~mm}$ ) within large Petri dishes (Corning, $150 \mathrm{~mm} \times 25 \mathrm{~mm}$ ). The dark treatment was watered, with $20 \mathrm{ml}$ of distilled water, and wrapped in aluminium foil in a dark room under red light of low intensity. The light treatment was also watered with $20 \mathrm{ml}$ of distilled water. The edge of the dishes was sealed with a strip of aluminium foil to ensure that the humidity was the same for both treatments. Petri dishes were then placed in a random order in an incubator (Sanyo, MLR 350HT) at a constant temperature of $36{ }^{\circ} \mathrm{C}$ with light $(198 \pm 34 \mu \mathrm{mol}$ photons $\left.\mathrm{m}^{-2} \mathrm{~s}^{-1}\right)$. After 10 days the number of germinated seed was assessed.

Influence of Temperature and Water Potential on Seed Germination

In each experiment, $0.3 \mathrm{~g}$ of fuzz was used with the exception of cross $98^{*} 148$ where $0.15 \mathrm{~g}$ of fuzz was used. Fuzz was well spread onto filter paper laid down into large Petri dishes (as described above). Dishes were watered with $20 \mathrm{ml}$ of distilled water, placed in zip-lock bags containing a wet paper towel to maintain a water saturated atmosphere and then placed in an incubator at the required temperature in constant light (198 \pm $34 \mu \mathrm{mol}$ photons $\mathrm{m}^{-2} \mathrm{~s}^{-1}$ ).

The influence of temperature on sugarcane seed germination at $18^{\circ} \mathrm{C}, 24^{\circ} \mathrm{C}, 27^{\circ} \mathrm{C}, 30^{\circ} \mathrm{C}, 36^{\circ} \mathrm{C}$ and $42^{\circ} \mathrm{C}$ was tested. Observation on the number of germinated seeds (visible protrusion of the radicle) were carried out commencing $24 \mathrm{~h}$ after incubation, initially every $3 \mathrm{~h}$, then less frequently, until no further germination was observed. The relative percentage of germination of seed from each cross was calculated at each temperature using the mean final number of germinated seed at $30{ }^{\circ} \mathrm{C}$ as $100 \%$ which corresponded to actual numbers of germinated seeds for each cross of: $59 \pm 8(89 * 758), 78 \pm 2$ (91*684), $79 \pm 5(96 * 283), 81 \pm 4$ (98*148), $49 \pm 4$ (98*2), $70 \pm$ 4 (98*206), $59 \pm 5(98 * 217), 27 \pm 3(98 * 78)$.

The influence of water potential on seed germination at 0 , $-0.5,-0.75$ and $-1 \mathrm{MPa}$ was tested at $30^{\circ} \mathrm{C}$ under constant light $\left(198 \pm 34 \mu \mathrm{mol}\right.$ photons $\left.\mathrm{m}^{-2} \mathrm{~s}^{-1}\right)$ for four crosses $(89 * 758,98 * 148,98 * 206,98 * 217)$. Water potentials were generated with PEG 8000 (Sigma-Aldrich) according to Michel (1983) and verified using an osmometer (Vapro osmometer 5520, Wescor).

For each cross the relative percentage of germination was calculated compared to the mean final number of germinated seeds at $0 \mathrm{MPa}$.
Determination of the Base and Optimal Temperature and Water Potential for Seed Germination

The germination rates (mean of 5 replicates) at each time point for each of the different temperatures or water potentials were fitted to a 3 parameter Gompertz function:

$f(t)=a e^{-e^{(x-c) / b}}$

The resulting $\mathrm{a}, \mathrm{b}$ and $\mathrm{c}$ parameters were used to calculate the time to reach different cumulative germination values as described in Brunel et al. (2009). For each treatment, we selected two cumulative germination values $(y \%)$ within the exponential phase of germination: 30 and $50 \%$ for the temperature treatment and 30 and $45 \%$ for the water deficit treatment. For each treatment level, the time to reach these cumulative germination values was calculated and used to generate the graph of $1 /$ time to $y \%$ of germination as a function of treatment levels. The base temperature and base water potential of germination were obtained from the $\mathrm{x}$ intercept of the linear regression between these two factors when the linear relationship was strong $\left(r^{2}>0.95\right)$ (Dahal and Bradford 1994).

For the temperatures tested, the optimal temperature of germination was defined as the temperature at which the time to reach $50 \%$ of germination was the smallest.

\section{Statistical Analyses}

Two sided t-tests were performed to test for significant effect $(p<0.05)$ of light on seed germination. Differences in the final number of germinated seeds for the temperature and water potential experiments were assessed by one way analysis of variance and pair wise multiple comparison with Holm-Sidak post hoc analysis used to compare the final number of germinated seeds between temperatures or water potentials.

Acknowledgments We thank SRA (formerly known as BSES Ltd) for supplying the seeds. We would like to thank Rosanna Powell, Juan José Olivares-Villegas, Nils Berding and Suzanne Schmidt, for their preliminary work on seed germination. Finally we would like to acknowledge the support from the Australian government through the SRDC for the project grant.

Open Access This article is distributed under the terms of the Creative Commons Attribution License which permits any use, distribution, and reproduction in any medium, provided the original author(s) and the source are credited.

\section{References}

Berding N, Hurney AP (2005) Flowering and lodging, physiologicalbased traits affecting cane and sugar yield: what do we know of their 
control mechanisms and how do we manage them? Field Crop Res 92:261-275

Bonnett GD, Olivares-Villegas JJ, Berding N, Morgan T (2010) Sugarcane sexual reproduction in a commercial environment: research to underpin regulatory decisions for genetically modified sugarcane. Proc Aust Soc Sugar Cane Technol 32:1-9

Bonnett G., Kushner J. and Saltonstall K. (2014) The reproductive biology of Saccharum spontaneum L.: implications for management of this invasive weed in panama. NeoBiota, 20: 61-79

Breaux RD, Miller JD (1987) Seed Handling, germination and seedling propagation. In: Heinz D (ed) J (ed) Developments in Crop Science. Elsevier, Amsterdam, pp 385-407

Brunel S, Teulat-Merah B, Wagner M-H, Huguet T, Prosperi JM, Dürr C (2009) Using a model-based framework for analysing genetic diversity during germination and heterotrophic growth of Medicago truncatula. Ann Bot 103:1103-1117

Buddenhagen IW (1977) Resistance and vulnerability of tropical crops in relation to their evolution and breeding. Ann N Y Acad Sci 287:309-326

Bureau of Meteorology (2014) Climate Data Online. http://www.bom. gov.au/climate/data/. Accessed 02 Sep 2014

Cazalet K. R. and Berjak P. (1983) Isolation of a seed storage fungus from sugarcane seeds. Proceedings of the South African Sugar Technologists' Association, June, 1983, pp. 105-108

Cheavegatti-Gianotto A, De Abreu HMC, Arruda P, Bespalhok Filho JC, Burnquist WL, Creste S, Di Ciero L, Ferro JA, De Oliveira Figueira AV, De Sousa Filgueiras T, Grossi-De-Sá MDF, Guzzo EC, Hoffmann HP, De Andrade Landell MG, Macedo N, Matsuoka S, De Castro Reinach F, Romano E, Da Silva WJ, De Castro Silva Filho M et al (2011) sugarcane (Saccharum x Officinarum): a reference study for the regulation of genetically modified cultivars in Brazil. Trop Plant Biol 4:62-89

Cuadrado A, Acevedo R, Moreno Díaz De La Espina S, Jouve N, De La Torre C (2004) Genome remodelling in three modern S. officinarum $\times$ S. spontaneum sugarcane cultivars. J Exp Bot 55:847-854

Dahal P, Bradford KJ (1994) Hydrothermal time analysis of tomato seed germination at suboptimal temperature and reduced water potential. Seed Sci Res 4:71-80

Donaldson RA (2009) Season effects on the potential biomass and sucrose accumulation of some commercial cultivars of sugarcane, $\mathrm{PhD}$ thesis. University of KwaZulu-Natal, Pietermaritzburg, South Africa

Dutt NL, Krishnaswami MK, Subba Rao KS (1937) A note on seedsetting and seed-germination in certain sugarcanes. Indian J Agric Sci 8:429-433

Frankland B, Taylorson R (1983) Light control of seed germination. In: Mohr H (ed) Shropshire JR W. Photomorphogenesis. SpringerVerlag, Berlin, pp 428-456

Garcia-Huidobro J, Monteith JL, Squire GR (1982) Time, temperature and germination of pearl millet (Pennisetum typhoides S.\&H.). J Exp Bot 33:288-296

Hampson CR, Simpson GM (1990) Effects of temperature, salt, and osmotic potential on early growth of wheat (Triticum aestivum). I. Germination. Can J Bot 68:524-528

Harris D, Hamdi QA, Terry Oda AC (1987) Germination and emergence of Sorghum bicolor: Genotypic and environmentally induced variation in the response to temperature and depth of sowing. Plant Cell Environ 10:501-508

Heinz DJ (1974) Temperature effect on fuzz (true seed) germination. Ann Rep Exp Station Hawaii Sugar Planter's Assoc 1:7-7

Holst-Jensen A (2009) Testing for genetically modified organisms (GMOs): past, present and future perspectives. Biotechnol Adv 27: 1071-82

Hsu SY (2001) Germinabilty of sugarcane fuzz. Rep Taiwan Sugar Res Inst 172:1-16

Humbert RP (1968) The growing of sugar cane. Elsevier, Oxford

Inman-Bamber N. G., Muchow R. C., Holden J. R., Roberston M. J. and Ham G. J. (1998) Soil water extraction by sugar cane beyond the readily available limit. Proceedings of the Australian Society of Sugar Cane Technologists, 1998, pp. 112-117

Itabari JK, Gregory PJ, Jones RK (1993) Effects of temperature, soil water status and depth of planting on germination and emergence of maize (Zea mays) adapted to semi-arid eastern Kenya. Exp Agric 29:351-364

Itakura M, Kudo M, Nakasone S (1981) Effect of temperature on sugarcane seed germination. Jpn J Trop Agric 25:17-51

Lakshmanan P, Geijskes RJ, Aitken KS, Grof CLP, Bonnett GD, Smith GR (2005) Sugarcane biotechnology: the challenges and opportunities. In Vitro Cell Dev Biol Plant 41:345-363

Lee S, Loo YS (1958) Report of some experiments on the germination of true sugarcane seed. Rep Taiwan Sugar Exp Station 18:1-13

Mcintyre CL, Jackson PA (2001) Low level of selfing found in a sample of crosses in Australian sugarcane breeding programs. Euphytica 117:245-249

Michel BE (1983) Evaluation of the water potentials of solutions of polyethylene glycol 8000 both in the absence and presence of other solutes. Plant Physiol 72:66-70

Moore PH, Paterson AH, Tew T (2014) Sugarcane: the crop, the plant, and domestication. In: Moore PH, Botha FC (eds) Sugarcane: physiology, biochemistry and functional biology. Wiley Blackwell, Oxford, pp 1-17

OECD (2013) Consensus document on the biology of sugarcane (Saccharum spp). http://www.oecd.org/officialdocuments/ publicdisplaydocumentpdf $/$ ? cote $=$ env $/ \mathrm{jm} / \mathrm{mono} \% 282013 \%$ 2922\&doclanguage $=$ en. Accessed 02 Sep 2014

OGTR (2011) The biology of the Saccharum spp (sugarcane). http:// www.ogtr.gov.au/internet/ogtr/publishing.nsf/content/sugarcane-3/ \$FILE/biologysugarcane11.pdf. Accessed 02 Sep 2014

Olivares-Villegas JJ, Berding N, Morgan T, Bonnett GD (2010) Sugarcane: identifying potential risks from sexual reproduction. Proc Int Soc Sugar Cane Technol 27:1-9

Paoletti C, Flamm E, Yan W, Meek S, Renckens S, Fellous M, Kuiper H (2008) GMO risk assessment around the world: some examples. Trends Food Sci Technol 19:70-78

Poljakoff-Mayber A (1959) Germination of the seeds of Saccharum aegyptiacum Willd. Bull Res Counc Isr 7:93-96

Saltonstall K, Bonnett G (2012) Fire promotes growth and reproduction of Saccharum spontaneum (L.) in Panama. Biol Invasions 14:2479 2488

Simpson GM (1990) Mutual influences of inflorescence and caryopsis parts on dormancy. In: Seed dormancy in grasses. Cambridge University Press, Cambridge, pp 60-113

Singh S (1988) Effect of temperature on germination of sugar cane seeds (fluff). Sugarcane 1:11-12

Singh S, Srivastava KK (1974) Effects of soil-water potential on germination of sugarcane setts. Indian J Agric Sci 44:184-187

Skinner JC (1959) Controlled pollination of sugarcane. Bur Sugar Exp Station: Tech Commun 1:7-20

Stoutt DG, Simpson GM, Flotre DM (1980) Drought resistance of Sorghum bicolor L. Moench. 3. Seed germination under osmotic stress. Can J Plant Sci 21:13-24

Tew TL, Pan Y-B (2010) Microsatellite (simple sequence repeat) markerbased paternity analysis of a seven-parent sugarcane polycross. Crop Sci 50:1401-1408

Waclawovsky AJ, Sato PM, Lembke CG, Moore PH, Souza GM (2010) Sugarcane for bioenergy production: an assessment of yield and regulation of sucrose content. Plant Biotechnol J 8:263-76

World Bank (2014) Climate Change Knowledge Portal. http://sdwebx. worldbank.org/climateportal/index.cfm. Accessed 02 Sep 2014

Wuest SB, Lutcher LK (2013) Soil water potential requirement for germination of winter wheat. Soil Sci Soc Am J 77:279283

Yang S-J, Chen J-B (1980) Germination response of sugarcane cultivars. Proc Int Soc Sugar Cane Technol 71:30-37 
Yoshida S (1981) Climatic environment and its influence. In: Fundamentals of Rice Crop Science. International Rice Research Institute, Los Baños, pp 65-109
Zhang H, Irving LJ, Mcgill C, Matthew C, Zhou D, Kemp P (2010) The effects of salinity and osmotic stress on barley germination rate: sodium as an osmotic regulator. Ann Bot 106:1027-35 